\title{
A Note on Testing for Environmental Kuznets Curves
}

\author{
Elbert DIJKGRAAF ${ }^{\odot}$ \\ Research Center for Economic Policy (OCFEB) \\ and \\ Herman R.J. VOLLEBERGH \\ Department of Economics and Research Center for Economic Policy (OCFEB) \\ Erasmus University Rotterdam
}

This version: May 20th 2001

OCFEB Research Memorandum 0103, 'Environmental Policy, Economic Reform and Endogenous Technology', Working Paper Series 7

JEL Codes: C 33; O 50; Q 40

Key words: Environmental Kuznets Curves, Panel Data, Heterogeneity.

We are grateful to Douglas Holtz-Eakin, John List, Bertrand Meelenberg, Richard Schmalensee and especially Rob Aalbers and Otto Swank, for useful comments and suggestions. Vollebergh would like to thank the Dutch Organization for Scientific Research (NWO) for financial support. 
Research Memorandum 0103

\section{OCFEB}

Room H6-21

Erasmus University Rotterdam

P.O. Box 1738

3000 DR Rotterdam

The Netherlands

Telephone +31 104082430

Telefax +31 104089173

E-mailinfo@ocfeb.nl

Website www.ocfeb.nl 


\section{Table of Contents}

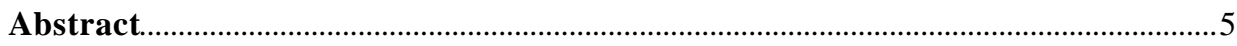

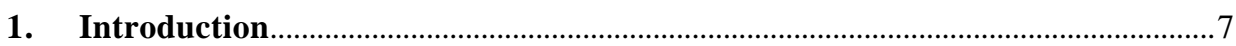

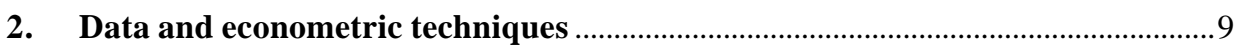

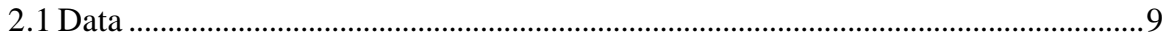

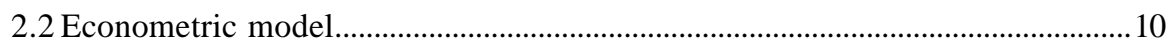

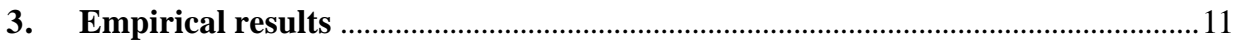

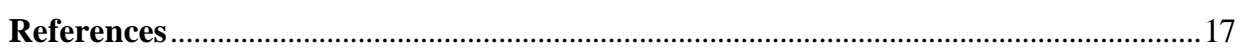

Appendix I Residuals panel model with country and year fixed effects ..................... 18

Appendix II Residuals panel model with country fixed effects and country specific trends ....................................................................................... 19

Appendix II Residuals time series models (no panel) ....................................................20 



\begin{abstract}
This paper casts doubt on empirical results based on panel estimations of an "invertedU" relationship between per capita GDP and pollution. Using a new data set for OECD countries on carbon dioxide emissions for the period 1960-1997, we find that the crucial assumption of homogeneity across countries is problematic. Decisively rejected are model specifications that feature even weaker homogeneity assumptions than are commonly used. Furthermore, our results challenge the existence of an overall Environmental Kuznets Curve for carbon dioxide emissions.
\end{abstract}





\section{Introduction}

In a recent contribution to this journal, Schmalensee, Stoker and Judson (1998) (SSJ hereafter) present forecasting results for the development of carbon dioxide $\left(\mathrm{CO}_{2}\right)$ emissions in this century. They base their structural projection model on panel-based evidence of an "inverse-U" relation between $\mathrm{CO}_{2}$ emissions per capita and per-capita income. Crucial to this evidence, however, is the assumption of homogeneity. Like other earlier contributions to estimating these "Environmental Kuznets Curves" (EKC) with panel data, SSJ assume that a typical cross-sectional unit follows this "inverse-U" pattern. The unit is expected to go first through a phase with a considerable growth in per capita $\mathrm{CO}_{2}$ emissions relative to per capita growth in GDP. Then, after having reached a peak (or "turning point"), it will show a decline in its per capita emissions at higher income levels.

This note explicitly tests for this assumption of homogeneity in panel models. ${ }^{1}$ To that end, we use a data set for OECD countries on $\mathrm{CO}_{2}$ emissions for the period 1960-1997. This panel is particularly useful for a study of the homogeneity assumption at the country level, because there is a wide overlap of observations of different countries at similar income levels. Moreover, the range of observations is long enough to test whether the slope coefficients for each country are sufficiently close to allow for panelbased estimations of an EKC for $\mathrm{CO}_{2}$. We find that homogeneity is strongly rejected at any conventional level of significance. This result holds for the common polynomial specifications of the estimated model, as well as for more flexible specificationsincluding the spline (piecewise linear) function used by SSJ.

Figure 1 illustrates the problem that arises. The figure shows a plot for two countries at the top income level of our panel, in particular the US and Japan. The US seems to be a typical example confirming the "inverted U" hypothesis. One first observes a considerable growth of per-capita $\mathrm{CO}_{2}$ emissions with per-capita GDP, then a peak somewhere in the mid70s, and, finally, a decrease at the highest income levels. Indeed, SSJ panel estimations for per capita carbon emissions also suggest a Turning Point for the US in 1973. The data for Japan, however, show a remarkable different pattern. There is not much evidence for an "inverted U". Nonetheless, SSJ's panel estimates also find a peak for Japan in 1973. This indicates the importance to have a closer look at the homogeneity assumption behind the panel estimations.

1 The empirical literature on EKC is still growing. Whereas most contributions have simply extended the seminal contribution of Grossman and Krueger (1995) to other data sets and environmental indicators, the recent literature seems somewhat more concerned with adequate model specification (see, for instance, de Bruyn, 2000, List and Gallett, 1999, and Harbaugh, Levinson and Wilson, 2000). 
Figure 1: Two typical heterogeneous patterns of $\mathrm{CO}_{2}$-emissions and GDP Growth

\section{1a US}

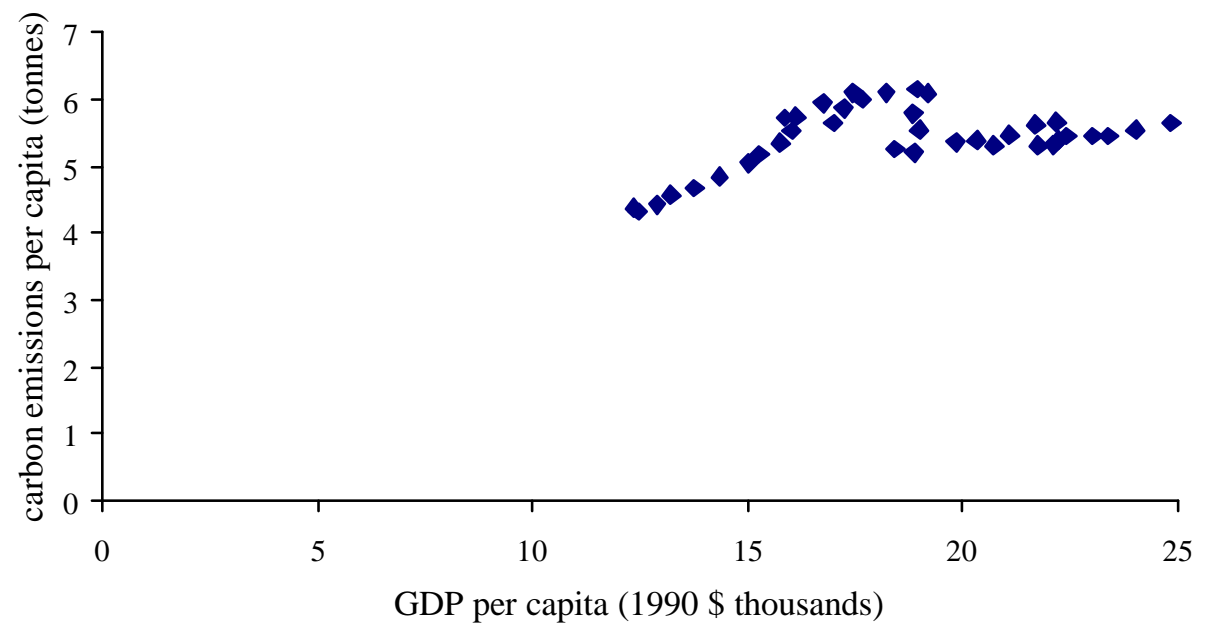

1b Japan

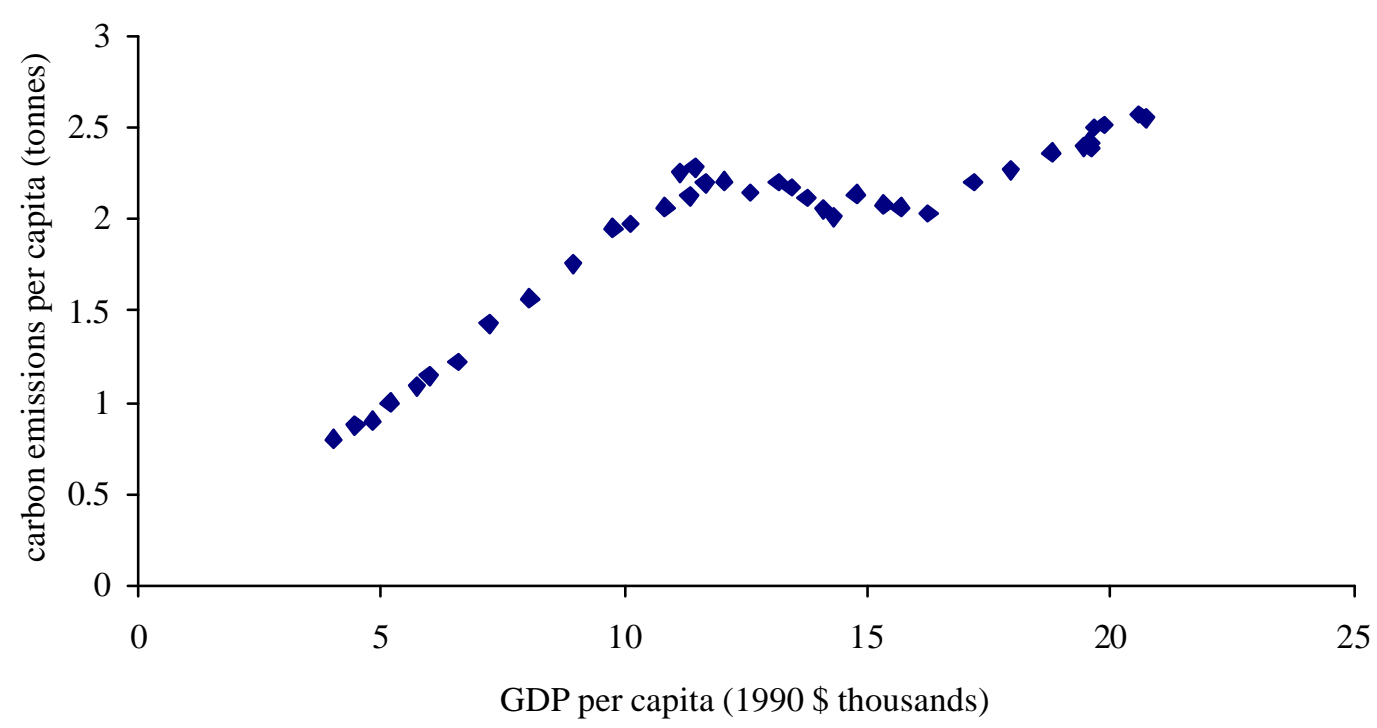


Our findings do not necessarily challenge the existence of an overall EKC for $\mathrm{CO}_{2}$ emissions in OECD countries. Although panel-based estimations are no longer appropriate, preliminary evidence based on time series suggests that eleven of the twenty-four OECD countries, including such countries as the US and Germany, still confirm the EKC hypothesis. Nonetheless, a caveat applies here. Because several countries do not reflect this pattern, it is rather unlikely that the overall IncomeEmission relationship is of the "inverted-U" type. Thus, there exists the serious risk that the environmental problem of climate change, with its large cross-country spillovers, will not become internalised "automatically" if countries grow richer.

This note is organised as follows. Section 2 describes our data set and briefly discusses the econometric model specification. Section 3 presents our results and compares them with other findings in the literature.

\section{Data and econometric techniques}

\subsection{Data}

Our results are based on national-level data for 24 OECD countries (excluding new members such as the Czech Republic, Hungary, Korea, Mexico and Poland) between 1960 and 1997. We thus concentrate exclusively on the sub-sample of traditional OECD countries, which alone is responsible for $50 \%$ of overall world carbon dioxide emissions in 1996. The data included are the following:

$\mathrm{C}=\mathrm{CO}_{2}$ emissions from energy consumption, millions of metric tons of $\mathrm{C}$

$\mathrm{Y}=\mathrm{GDP}$, millions of 1990 US dollars

$\mathrm{N}=$ population

$\mathrm{E}=$ energy consumption, million Tons of Oil Equivalent (TOE)

Our overall data set contains 912 observations on these variables; for each country we have 38 observations.

Data on C are calculated from E, using OECD (2000) and IEA (1991). To calculate $\mathrm{CO}_{2}$ emissions, we use data for Total Primary Energy Supply (TPES) per fuel, corrected for non-energy use of fuels such as chemical feedstocks. Fuels incorporated in the calculations are coal, other solid fuels (wood, for example), crude oil, petroleum products and natural gas. Total energy use per country, as well as emissions, are corrected for exports and imports of fuels, as well as for stock changes and international marine bunkers. ${ }^{2}$

2 Our procedure in calculating $\mathrm{CO} 2$ emissions from OECD energy consumption data is similar to the approach followed by the Oak Ridge National Laboratory (ORNL), whose data are usually included in empirical research on $\mathrm{CO} 2$ emissions (see Holtz-Eakin and Selden, 1995, and SSJ, who built on the work of the previous authors). 
Data on $\mathrm{Y}$ and $\mathrm{N}$ were taken from the OECD Energy Balances. All figures are expressed in 1990 dollars, using purchasing power parities. Time coverage of these data is considerably more recent compared to the widely used Penn World Table, which has figures only until 1992. The data on Germany require some additional attention due to the country's unification in 1991. The OECD reconstructed data on Y for Germany as a whole (including the former GDR) for the years between 1970 and 1989. We further extrapolated GDP figures backward until 1960, using adjusted GDP levels for Western Germany with the number of inhabitants of Eastern Germany.

\subsection{Econometric model}

To maintain as much consistency as possible with other studies on EKC, we focus mainly on polynomial specifications of country-level emissions as a function of each country's per capita income, allowing for both country- and time (fixed) effects-but we also include the spline function approach applied by SSJ. Thus, we test different specifications of the following log-linear equation:

$$
\begin{aligned}
& \ln \left(c_{i t}\right)=\sum_{k=1}^{K} a_{k i}\left[\ln \left(y_{k i t}\right)\right]+\alpha_{i}+G(t)+\varepsilon_{i t} \\
& \text { with } \mathrm{i}=1,2, \ldots, 24 ; \mathrm{t}=1960,1961, \ldots, 1997 ; \mathrm{k}=1,2, \ldots \mathrm{m}
\end{aligned}
$$

and where $\mathrm{c}=\mathrm{C} / \mathrm{N}, \mathrm{y}=\mathrm{Y} / \mathrm{N}$, the $\alpha_{\mathrm{i}}$ are country-fixed effects, $G$ is some function of time, and $\varepsilon_{i t}$ is the error term. Furthermore, $a_{k i}$ is the unknown vector of potentially heterogeneous slope coefficients, and $y_{k i t}$ is the vector of $\mathrm{K}$ exogenous income parameters for country $i$ at time t. As explained by SSJ, the $\alpha_{i}$ term reflects persistent country-specific differences, such as fossil fuel availability and prices, regulatory differences and preferences, allowing for vertical shifts of the emission-income relationship across countries. The $G(t)$ term picks up changes over time, like changing (oil) prices, technologies in use, regulations (standards as well as taxes and subsidies) and preferences.

The general premise behind testing (1) is that a single cross-sectional unit undergoes the inverted-U relationship over time. The common procedure is to allow only for countryspecific heterogeneous intercepts, and not for heterogeneous slope parameters. We explicitly tested for the assumption that all countries follow an isomorphic pattern for $\mathrm{CO}_{2}$ emissions in relation to GDP. More precisely, we tested the null hypothesis of similarity between the country and panel parameters for all countries (whether $a_{k i}=a_{k}$ )

3 The general specification allows not only for the traditional EKC specification with timefixed effects $(G(t)=\beta t$ ), but also for a general time trend (with $G(t)=\beta t$ ), and a countryspecific time coefficient (with $G(t)=\beta i \mathrm{t}$ ). Note that by adding more flexibility to the time parameter through country-specific time trends, the $\beta$ i coefficient also captures differences 10 in these changes over time, across countries. 
with different degrees of heterogeneity in the control variables (including country-fixed effects as well as country-specific trends), and for both the polynomial and spline specification of (1). ${ }^{4}$ For descriptive statistics for all variables, see Table 1.

Table 1: Descriptive statistics ${ }^{\mathrm{a} b}$

\begin{tabular}{lccc}
\hline Variable & Mean (SD) & Minimum & Maximum \\
\hline Per Capita Carbon & 2,595 & 167 & 12,333 \\
Per Capita Income (1990\$) & 12,682 & 2,771 & 29,081 \\
Population (mln) & 32.7 & 0.2 & 266.8
\end{tabular}

a) Descriptive statistics are for the 24 OECD countries for the period 1960-1997 $(n=912)$.

b) Emission levels are measured in tons.

\section{Empirical results}

Table 2 summarises our results for three different panel estimations of the cubic polynomial specification of (1). ${ }^{5}$ The first two columns reflect the commonly used 'traditional models' to test for EKC, allowing only for intercept heterogeneity. The response coefficients (significant at 99\%) together nicely reflect the inverted-U. This suggests that after OECD countries reach a critical level of income (per capita), their (per capita) emissions drop. The estimated turning points, or peaks, for both models do not differ much $-\$ 15,704$ for the model with country-fixed effects only, and $\$ 13,959$ for the model with both country- and time-fixed effects, corresponding to $54 \%$ and $48 \%$ of the maximum sample GDP, respectively $(\$ 29,081)$.

Interestingly, this result confirms the findings of SSJ (1998), who report a within sample turning point for $\mathrm{CO}_{2}$ based on their spline estimation of a data set including non-OECD countries. Earlier contributions based on polynomial specifications only reported a turning point located far out of sample (see Shafik, 1994, and Holtz-Eakin and Selden

4 This approach is slightly different from List and Gallett (1999). They showed the importance of slope heterogeneity using a data set for $\mathrm{SO}_{2}$ and $\mathrm{NO}_{\mathrm{x}}$ for different states in the US using a SUR estimation. List and Gallett (1999), however, do not test for the spline specification.

5 We present results only for the cubic model because the quadratic models were all clearly rejected vis-à-vis the cubic specifications. Furthermore, both the quadratic and cubic models without any fixed effects were also rejected. Response coefficients for the quadratic model, as well as for models with country-fixed effects and time-fixed effects, are available upon request. 
(HES), 1995). The similarity of our findings with those of SSJ, however, is not really surprising. Indeed, in their case the richest countries of the world, i.e. OECD countries, are responsible for the downward trend at the highest income levels (see, in particular, SSJ 1998, pp.19-20); these are precisely the countries that are represented in our data set.

Table 2:Summary estimates for Environmental Kuznets Curves for different cubic model specifications ${ }^{\text {a }}$

\begin{tabular}{|c|c|c|c|}
\hline & \multicolumn{2}{|c|}{ Traditional Model $^{\mathrm{b}}$} & \multirow{2}{*}{$\begin{array}{c}\text { General Model }^{\mathrm{c}} \\
\begin{array}{c}\text { Country } \\
\text { heterogeneity }\end{array}\end{array}$} \\
\hline & $\begin{array}{l}\text { Country-fixed } \\
\text { effects }\end{array}$ & $\begin{array}{l}\text { Time- and country- } \\
\text { fixed effects }\end{array}$ & \\
\hline \multicolumn{4}{|l|}{ Independent variables } \\
\hline \multirow[t]{2}{*}{ GDP } & -27.02 & -31.55 & -42.20 \\
\hline & $(8.38)$ & (8.46) & (7.02) \\
\hline \multirow[t]{2}{*}{$\mathrm{GDP}^{2}$} & 3.77 & 4.27 & 5.05 \\
\hline & $(0.92)$ & $(0.93)$ & $(0.77)$ \\
\hline \multirow[t]{2}{*}{$\mathrm{GDP}^{3}$} & -0.16 & -0.18 & -0.19 \\
\hline & $(0.03)$ & $(0.03)$ & $(0.03)$ \\
\hline Fixed-effects countries & Yes $^{\mathrm{d}}$ & $\mathrm{Yes}^{\mathrm{d}}$ & $\mathrm{Yes}^{\mathrm{d}}$ \\
\hline Fixed-effects years & & Yes $^{\mathrm{d}}$ & \\
\hline Country-specific trend & & & Yes $^{\mathrm{d}}$ \\
\hline Observations & 912 & 912 & 912 \\
\hline \multicolumn{4}{|l|}{ Turning-point estimates } \\
\hline Estimated turning point (1990\$) & 15,704 & 13,959 & \\
\hline Unweighted mean turning point & & & 20,647 \\
\hline Turning point (\% max. panel) ${ }^{\mathrm{e}}$ & 54 & 48 & 71 \\
\hline \multicolumn{4}{|l|}{ Homogeneity tests } \\
\hline F (GDP variables) & $46.36^{* * * \mathrm{f}}$ & $65.11^{* * * \mathrm{f}}$ & $16.63^{* * * \mathrm{f}}$ \\
\hline F (country-specific trends) & & & $73.78^{* * * \mathrm{~g}}$ \\
\hline $\mathrm{F}$ (all variables) & & & $54.02^{* * * \mathrm{~h}}$ \\
\hline
\end{tabular}

a) Dependent variable is $\mathrm{CO}_{2}$ emissions per capita; standard errors in parentheses under coefficient estimates.

b) Traditional models allow heterogeneous intercepts, but assume slope homogeneity.

c) General model allows for both intercept and slope heterogeneity.

d) Available upon request.

e) As a percentage of maximum GDP panel (Luxembourg \$29,081).

f) F-test with $\mathrm{H}_{0}: \mathrm{a}_{1 \mathrm{i}}=\mathrm{a}_{1 \mathrm{i}+1}$ and $\mathrm{a}_{2 \mathrm{i}}=\mathrm{a}_{2 \mathrm{i}+1}$ and $\mathrm{a}_{3 \mathrm{i}}=\mathrm{a}_{3 \mathrm{i}+1}$.

g) F-test with $\mathrm{H}_{0}: \beta_{\mathrm{i}}=\beta_{\mathrm{i}+1}$.

h) F-test with $\mathrm{H}_{0}: \mathrm{a}_{1 \mathrm{i}}=\mathrm{a}_{1 \mathrm{i}+1}$ and $\mathrm{a}_{2 \mathrm{i}}=\mathrm{a}_{2 \mathrm{i}+1}$ and $\mathrm{a}_{3 \mathrm{i}}=\mathrm{a}_{3 \mathrm{i}+1}$ and $\beta_{\mathrm{i}}=\beta_{\mathrm{i}+1}$.

(**** Significant at $99 \%$ confidence interval). 
Unfortunately, the null hypothesis of homogeneous country-specific slopes (whether $a_{k i}$ $=a_{k}$ ), which is at the core of the traditional models, is clearly rejected at the usual level of $99 \%$ significance. The magnitude of the $F$-test for the model with country-fixed effects only, and the model with both time- and country-fixed effects, is $F(69816)=$ 46.36 and $F(69779)=65.11$, respectively (see Appendix I for a plot of the residuals of the last model). This result does not change if one allows for more flexibility in the time parameter by including country-specific trends (see the last column of Table 2). This more general model performs considerably better than the commonly estimated traditional models. It also maintains the finding of a within-sample turning pointalthough at a higher level. However, the homogeneity assumption on the GDP coefficients is still rejected (the $F$-statistic is $F(69792)=16.63$; see Appendix II and III for a plot of the residuals). ${ }^{6}$

The importance of heterogeneity is further illustrated by including country-specific GDP variables for one country at a time in the panel model. Using a $L R$ test, we have to reject the hypothesis of homogeneity for 14 of the 24 countries at a $99 \%$ level of significance (using the preferred model with country-specific trends). ${ }^{7}$ Furthermore, by systematically testing the homogeneity of all possible sub-panels (in total, nearly 380,000 combinations are checked), we also found that sub-panels for which homogeneity is not rejected are rare, and never exceed a group of five countries. Moreover, even for very small sub-panels, homogeneity is rejected in nearly all cases. Thus, even for an apparently homogeneous group of OECD countries, panel-based estimates for commonly used polynomial estimators do not seem to allow for enough

6 We generate our F-statis tics by comparing the sum of squared residuals of the general model with and without heterogeneous coefficients for either only the GDP variables ('traditional models') and/or the time-specific trend variable (general model). Because in the last case all coefficients are country-specific, we estimated this model with time-series analysis. Although using the Seemingly Unrelated Regressions (SUR) model potentially increases the efficiency of estimation, the sum of squared residuals for our data is larger under SUR (3.43 versus 2.44), indicating that time-series estimates are preferable. Also, $51 \%$ of the individual residuals do not improve with SUR. These results are consistent with our finding that testing of the general model is not possible, due to a near singular matrix.

7 Repeating this procedure by excluding countries with the largest LR statistics does not result in a panel for which homogeneity cannot be rejected. Not surprisingly, we also find the same results for models with a general trend or time-fixed effects. These results are available upon request. 
heterogeneity, and might yield biased and inconsistent parameter estimates for $\mathrm{CO}_{2}$ emissions. ${ }^{8}$

Further testing of homogeneity in the case of a spline (piecewise linear) function yields similar results. Like SSJ, we first started with a model featuring 20- and 24-segment splines and time-fixed effects, where each segment contains the same number of data points. In our case, we reject simplifications to 12 and 10 splines that preserve this symmetry, but the differences are small. The same holds for simplifications from 16 to 8 splines. Again, including a country-specific trend improves the explanatory power and allows us to reduce the number of splines to 12,10 and 8 , respectively. ${ }^{9}$ As far as the homogeneity assumption is concerned, we also find clear indications that even spline models with country-specific trends do not allow for enough heterogeneity. With the same income levels for the different segments applied to the country level, we find a rejection of this crucial assumption for the preferred models in all cases. ${ }^{10}$

Our findings suggest that panel-based estimations of the inverted-U hypothesis for $\mathrm{CO}_{2}$ are inconsistent. This holds true, not only for polynomial, but also for spline-based specifications of (1). To further illustrate the significance of our result for the EKC hypothesis, we compare country-specific income parameter estimates for the general polynomial model with time-series estimates. ${ }^{11,12}$ Table 3 shows that the panel estimates

8 One obvious objection to our findings is that our results are sensitive to the data sets used. To check this sensitivity, we also tested whether the homogeneity hypothesis is rejected for the data sets used by HES and SSJ. We first tested for a sample period excluding data between 1990-1997. We also used income data taken from the Penn World Table until 1992 for the same (OECD) sample (this also accounts for potential problems with data on $\mathrm{Y}$ for Germany, as these data are restricted to West Germany only). Finally, we used emission figures for the same panel taken from the Carbon Dioxide Information Analysis Center of the Oak Ridge National Laboratory. In all of these cases our basic findings are similar. These results are available upon request.

9 The sum of squared residuals for these models is much lower than the sum of squared residuals for the models with a general trend and those with time-fixed effects, for all tested spline models. Fixed effects are always preferred to a general trend, although the differences are small (e.g. F(36 834) $=2.48$ for 16 splines). Not surprisingly, we find much higher differences between the models with country-specific trends and those with a general trend (e.g. $\mathrm{F}(23 \mathrm{856})=77.16$ for 8 splines). Therefore, we used this specification for further testing of the assumption of homogeneity.

10 For instance, the F-test on heterogeneous coefficients of the income variables for the 8spline model is $\mathrm{F}(140716)=11.67$. We found similar results for 12-, 10- and the (nonpreferred) 6- spline models. Results are available upon request.

11 For each country, we use the preferred time-series model, which usually includes a country-specific time trend (exceptions are Australia, Finland, Iceland, Italy, Norway, Spain, and Turkey). 
for almost all OECD countries have a within-sample turning point, while Greece and Turkey (the exceptions) do not fall in the highest income spline of SSJ.

Time-series estimates, however, present a strikingly different pattern. Still, 11 of the 24 countries now have a statistically significant turning point (also measured as the percentage of maximum GDP, 1997 level, of the panel), and therefore confirm the inverted-U hypothesis. Furthermore, of the 13 OECD countries (mentioned explicitly by SSJ) that had a within-sample turning point (all of them dated in the 70 s), only five countries confirm this picture based on our time-series estimates (Canada, Germany, Luxembourg, Switzerland, and the US). Also, the data for three of the seven highest income countries do not indicate a turning point according to our estimates. Finally, for 13 countries the gap between the estimated turning point based on panel data and its concomitant time series estimates is more than 100 percentage points.

Because these numbers are still significantly different from zero, the time-series estimates do not imply a rejection of the inverted-U hypothesis, in general. This ultimately will depend on the balance between the high-income countries with an (expected) inverted-U, and those high-income countries with a still-growing amount of (per capita) emissions. However, an overall inverted-U is doubtful if so many counterexamples exist at the country level. This suggests that much more work should be done on time-series estimates. ${ }^{13}$ Indeed, a lack of homogeneity with respect to $\mathrm{CO}_{2}$ should not come as a surprise, given the trends in international specialisation, and other differences in local circumstances, as well as the absence of (co-ordinated) policies against $\mathrm{CO}_{2}$ emissions in the past.

12 We do not include a comparison with our estimated spline models. The evidence we find is hardly conclusive, and not convincing. First, comparing spline estimates for each country with panel-based estimates does not add much to the widely divergent picture we already report for the polynomial models. Second, several spline coefficients are not significant for both the fixed-effect and the country-specific trend models - in particular for those models that include a larger number of splines. Third, the fixed-effect specification confirms the result of SSJ of an overall inverted-U pattern, although considerable variation exists in sign (and significance) for higher order splines (if included). The country-specific trend models do not reflect this inverted-U. However, estimating country-specific splines based on an arbitrary choice of the number and length of the segments for the panel as a whole is not convincing because of the relatively short time series available.

13 A recent paper on structural breaks in carbon emissions per capita by Liski and Toppinen (2001) confirms this result. Using much longer time series (1878-1994), they find evidence of a stable emission trend with a downturn in slope for six countries only. Furthermore, their endogenously determined structural breaks are mainly located at the beginning of the 20 th century, which suggests that the oil price shock cannot be seen as such an event. 
Table 3 Comparing turning points of panel with time-series estimates ${ }^{\text {a,b }}$

\begin{tabular}{|c|c|c|}
\hline Country & $\begin{array}{c}\text { Panel } \\
\text { With country-specific trend }\end{array}$ & $\begin{array}{l}\text { Time-series } \\
\text { preferred model }\end{array}$ \\
\hline & $\%$ maximum panel $^{\mathrm{c})}$ & $\%$ maximum panel ${ }^{\mathrm{c})}$ \\
\hline Australia & 84 & 108 \\
\hline Austria & 59 & NO \\
\hline Belgium & 45 & $\mathrm{NO}^{\mathrm{e})}$ \\
\hline Canada ${ }^{\mathrm{d})}$ & 61 & 54 \\
\hline Denmark $^{\mathrm{d})}$ & 77 & NO \\
\hline Finland & 87 & NO \\
\hline France & 40 & NO \\
\hline Germany & 66 & 50 \\
\hline Greece & 118 & NO \\
\hline Iceland & 48 & 50 \\
\hline Ireland & 68 & 61 \\
\hline Italy & 82 & NO \\
\hline Japan $^{\text {d) }}$ & 71 & NO \\
\hline Luxembourg d) & 34 & 43 \\
\hline Netherlands & 75 & $\mathrm{NO}$ \\
\hline Norway $^{\text {d) }}$ & 70 & $\mathrm{NO}$ \\
\hline New Zealand & 99 & NO \\
\hline Portugal & 96 & NO \\
\hline Spain & 87 & 44 \\
\hline Sweden & 30 & 44 \\
\hline Switzerland ${ }^{\text {d) }}$ & 97 & 68 \\
\hline Turkey & 106 & 60 \\
\hline United Kingdom & 31 & NO \\
\hline United States $\left.{ }^{d}\right)$ & 73 & 79 \\
\hline
\end{tabular}

a) Estimates for panel model with country-specific trend.

b) Time-series estimates based on preferred models for each country (usually with trend).

c) Maximum GDP is $\$ 29,081$ (Luxembourg).

d) Countries reaching income levels above $\$ 20,000$ per capita.

e) Peak at $30 \%$, and trough at $48 \%$. 


\section{References}

Bruyn, Sander M. de, Economic Growth and the Environment (Dordrecht: Kluwer Academic Publishers, 2000).

Grossman, Gene M. and Allen B. Krueger, "Economic Growth and the Environment," Quarterly Journal of Economics 110(2) (1995), 353-377.

Harbaugh, William, Arik Levinson and David Wilson (2000), Re-examining the Empirical Evidence for an Environmental Kuznets Curve (Cambridge MA: NBER, 2000).

Holtz-Eakin, Douglas and Thomas M. Selden, "Stoking the Fires? $\mathrm{CO}_{2}$ Emissions and Economic Growth," Journal of Public Economics 57 (1995), 85-101.

IEA/OECD, Greenhouse Gas Emissions: The Energy Dimension (Paris: OECD, 1991).

Liski, Matti and Anne Toppinen, Stochastic versus Deterministic Trends in Carbon Dioxide Time Series (Helsinki: Helsinki School of Economics, Working Paper, 2001).

List, John A. and Craig A. Gallet, "The Environmental Kuznets Curve: Does One Size Fit All?," Ecological Economics 31 (1999), 409-423.

OECD, Energy Balances, Statistical Compendium, ed. 01, CD-ROM (Paris: OECD, 2000).

Schmalensee, Richard, Thomas M. Stoker, and Ruth A. Judson, "World Carbon Dioxide Emissions: 1950-2050," The Review of Economics and Statistics, 80(1) (1998), 15 27.

Shafik, Nemat, "Economic Development and Environmental Quality: An Econometric Analysis," Oxford Economic Papers, 46(0) (1994), 757-773. 
Appendix IResiduals panel model with countryand year fixed effects

AUS Residuals

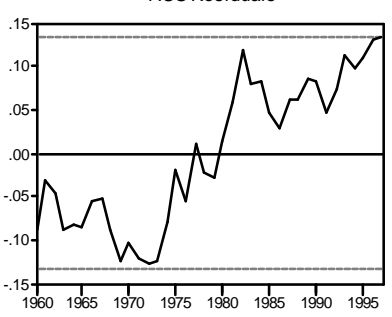

FIN Residuals

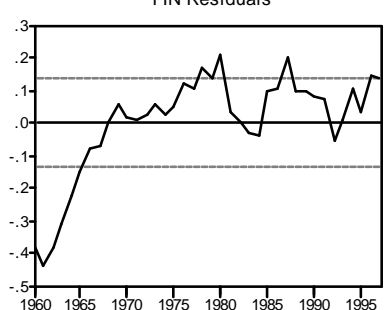

IRE Residual

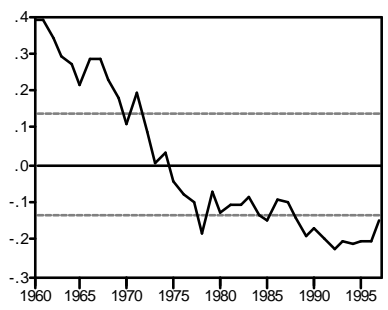

NOR Residuals
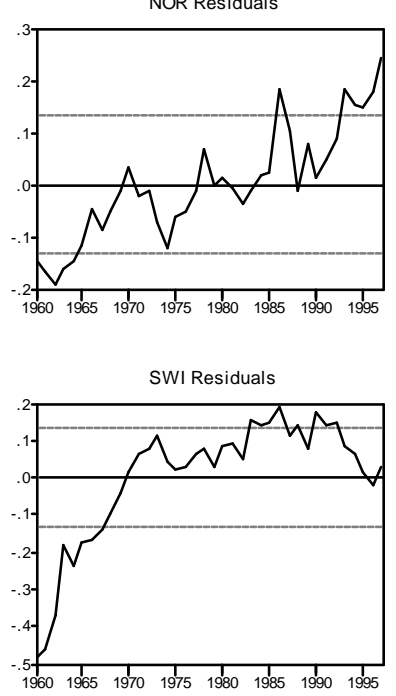

AUT Residuals
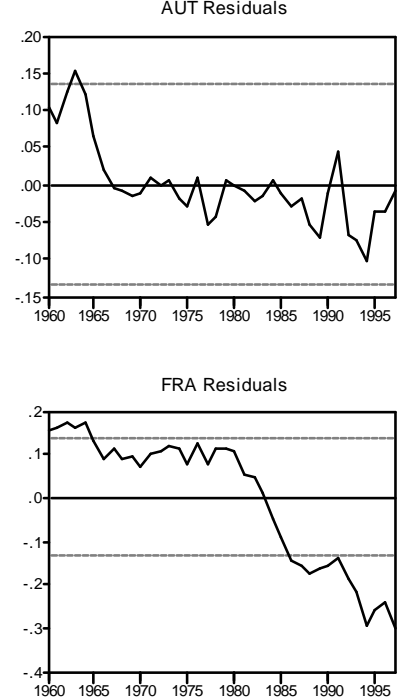

ITAResiduals

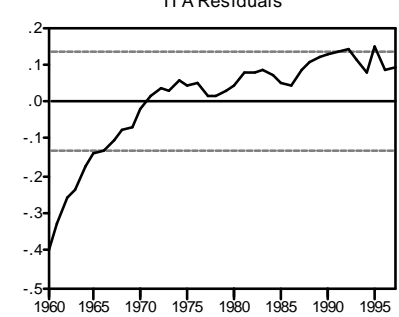

NZL Residuals
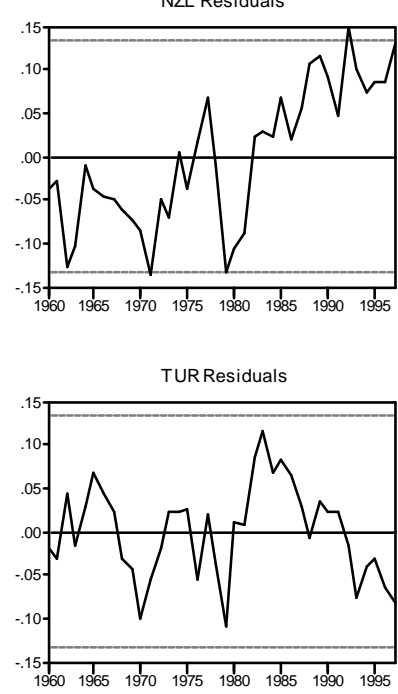

BEL Residuals
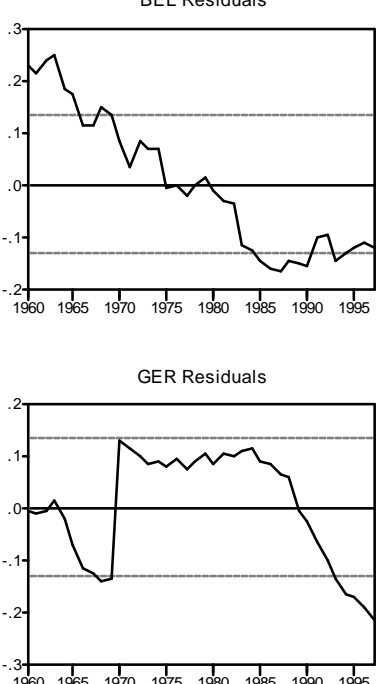

JPN Residuals

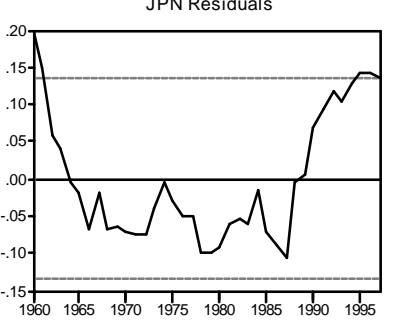

POR Residuals

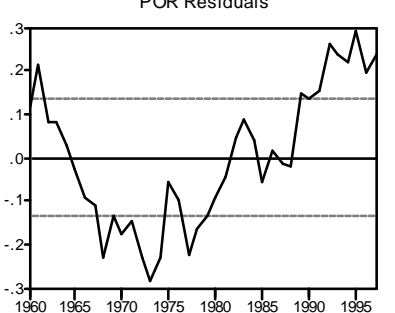

UKD Residuals

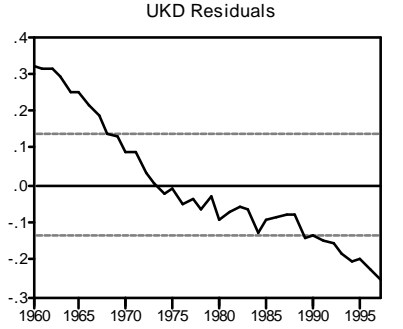

DNK Residuals

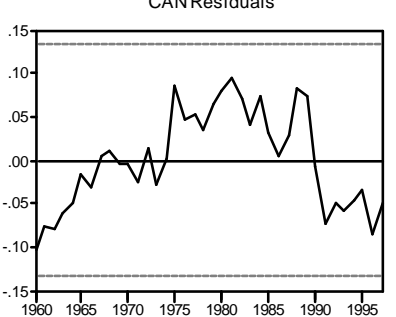

GRE Residuals

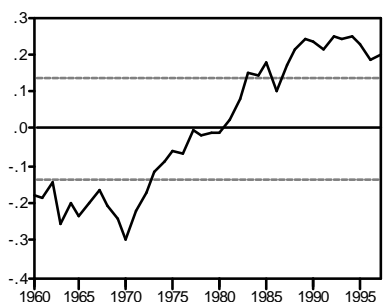

UX Residuals

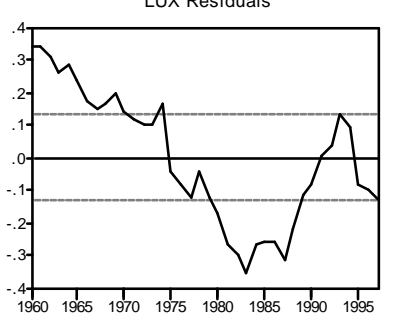

SPA Residuals
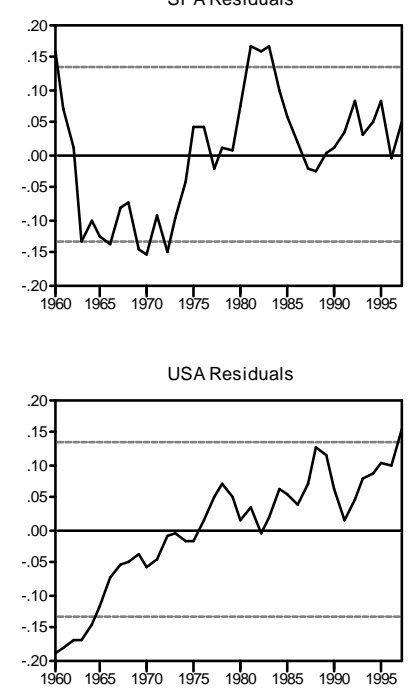
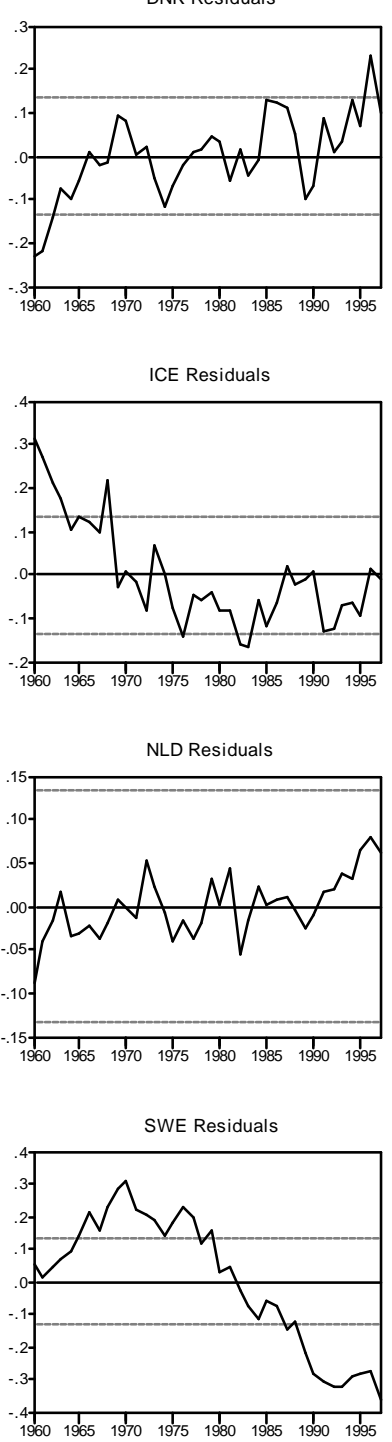

ICE Residuals

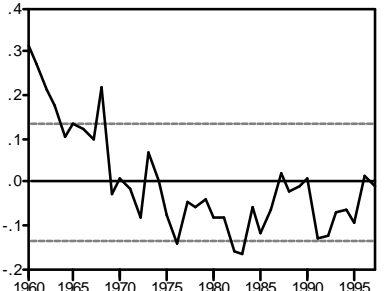

NLD Residuals

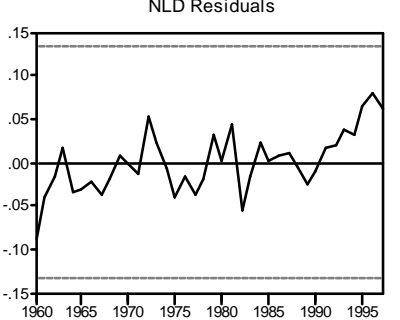

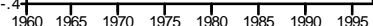


Appendix II Residuals panel model with country fixed effects and countryspecific trends

AUS Residuals

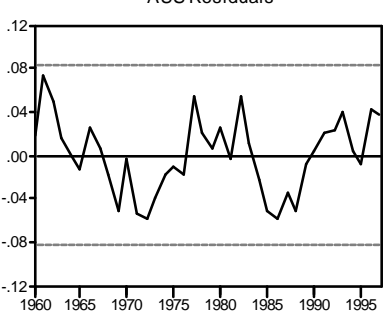

FIN Residuals

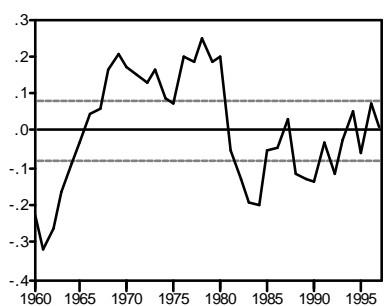

IRE Residuals

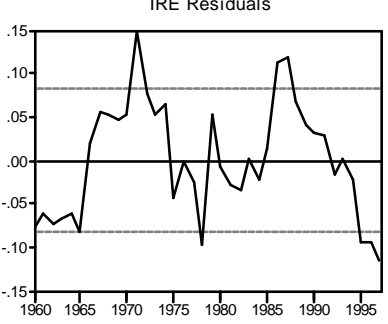

NOR Residuals

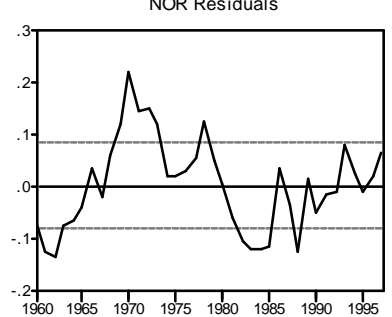

SWI Residual

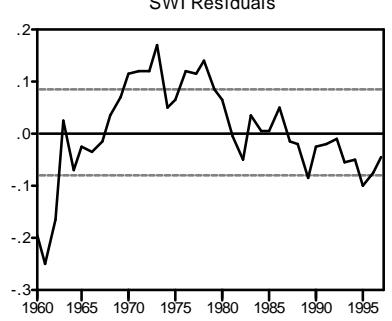

AUT Residuals
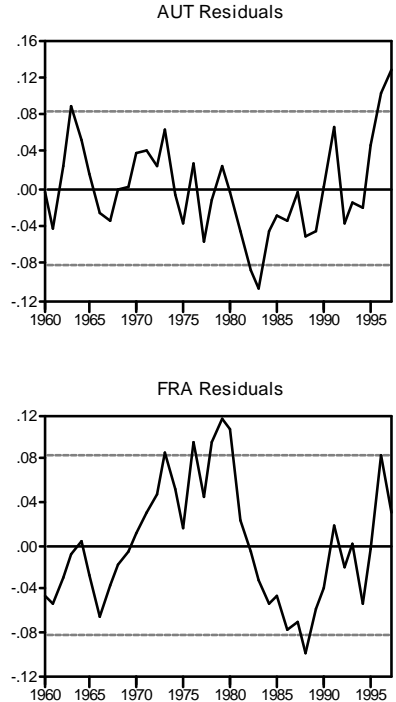

ITAResiduals

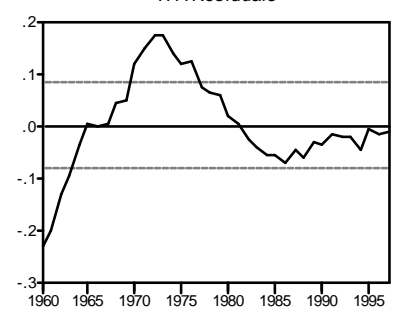

NZL Residuals

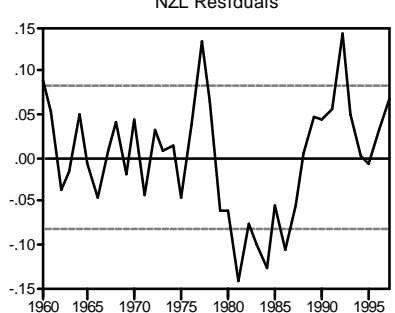

TURResiduals

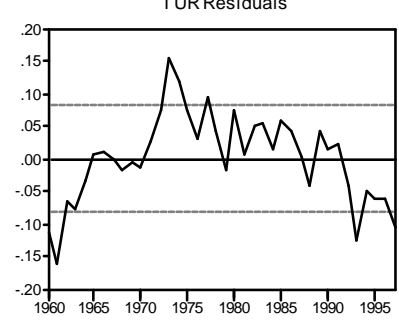

BEL Residuals

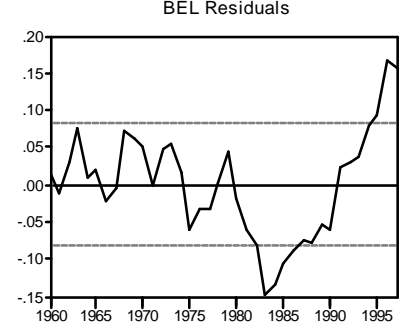

GER Residuals

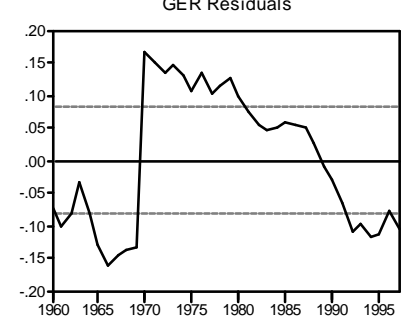

JPN Residuals

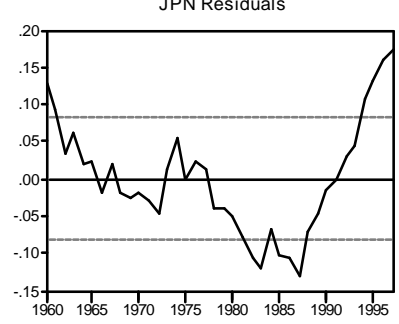

POR Residuals

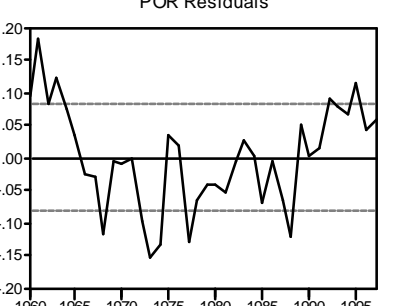

UKD Residuals

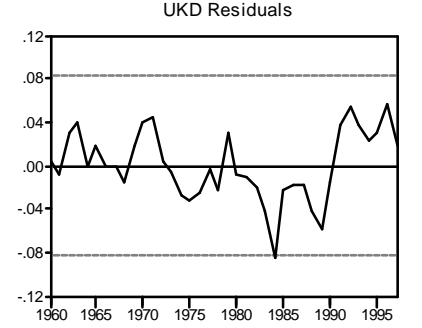

CAN Residuals

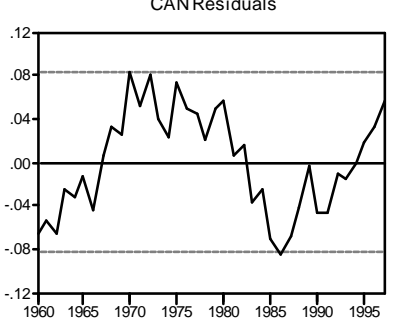

GRE Residuals

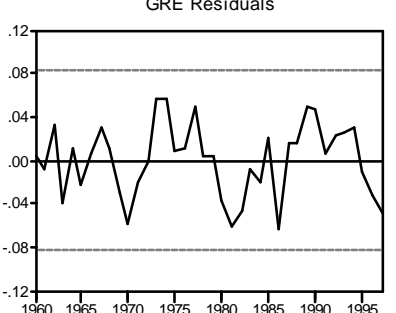

LUX Residuals

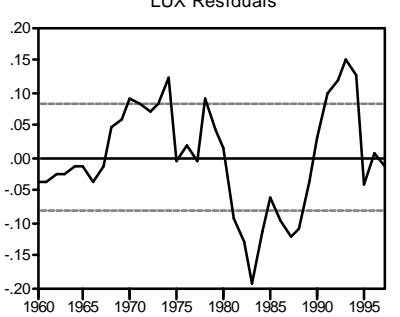

SPA Residuals

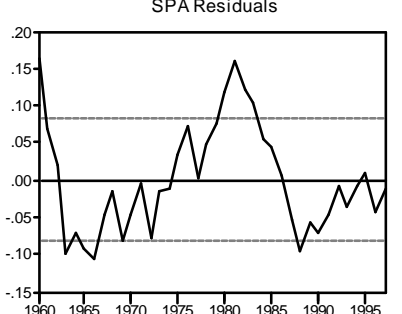

USA Residuals

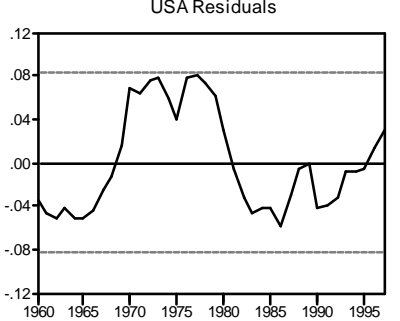

DNK Residuals

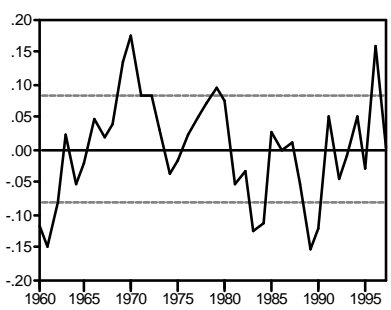

ICE Residuals

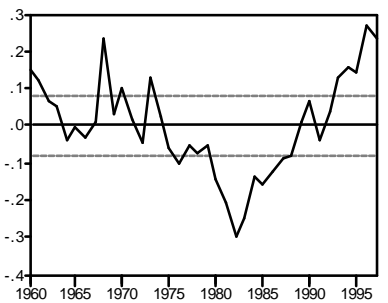

NLD Residuals

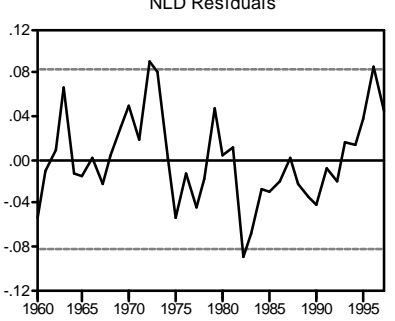

SWE Residuals

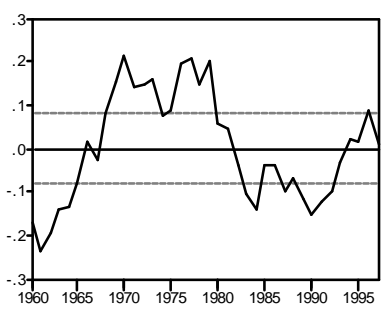


Appendix III Residuals time series models (no panel)

AUS Residuals

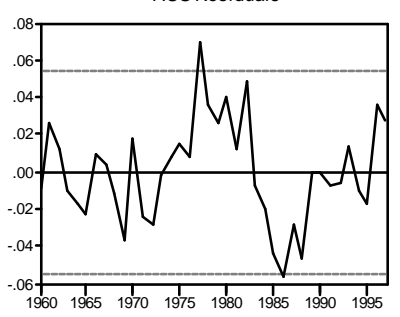

FIN Residuals

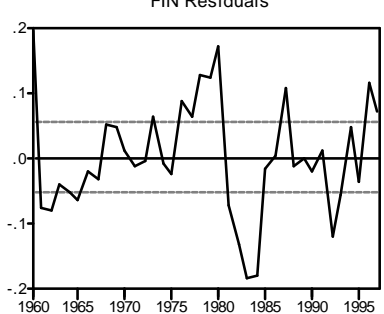

RE Residuals

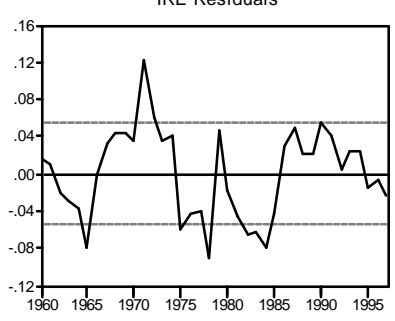

NOR Residuals

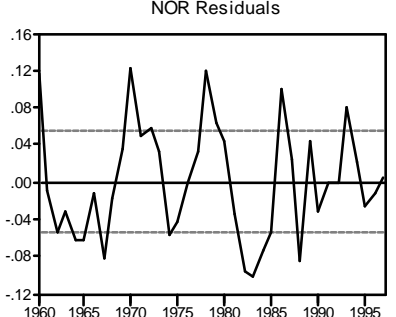

SWI Residuals

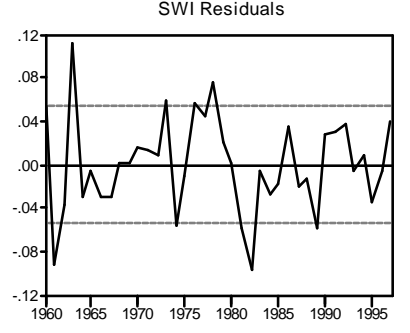

AUT Residuals

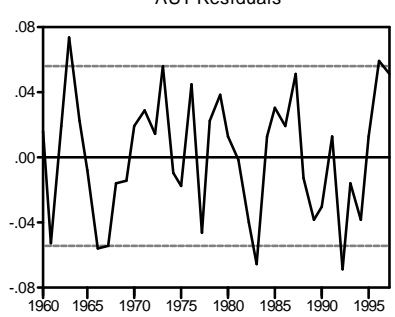

FRA Residuals

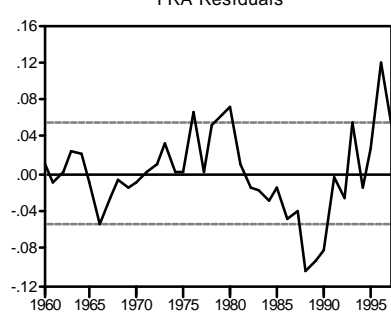

ITAResiduals

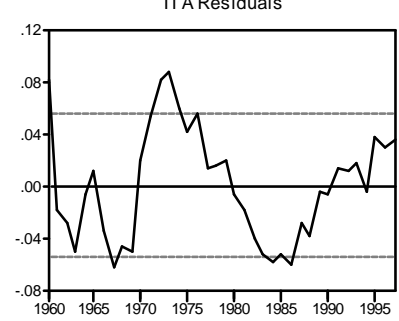

NZL Residuals

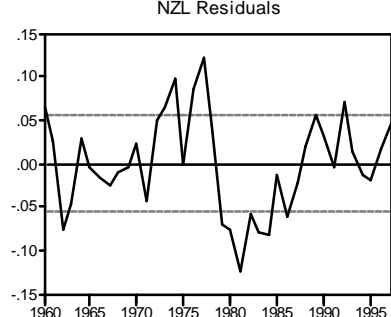

TURResiduals

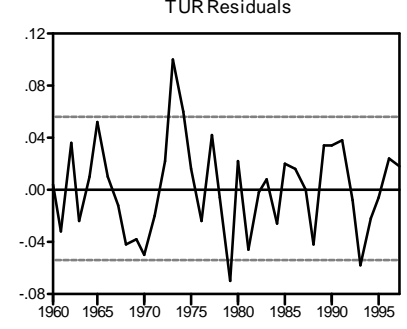

BEL Residuals

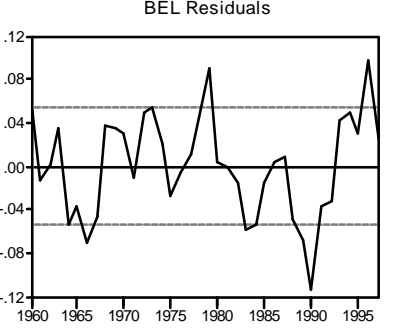

GER Residuals

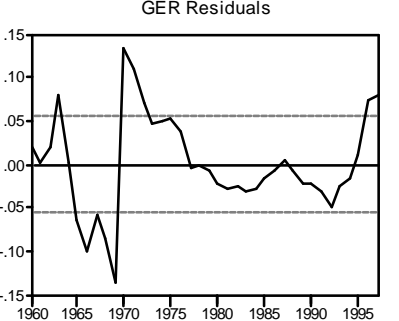

JPN Residuals

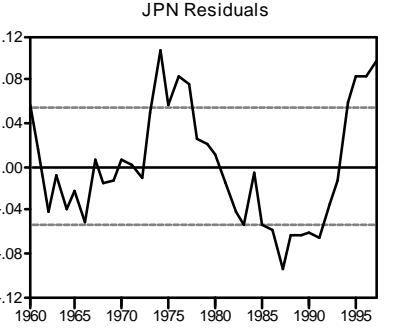

POR Residuals

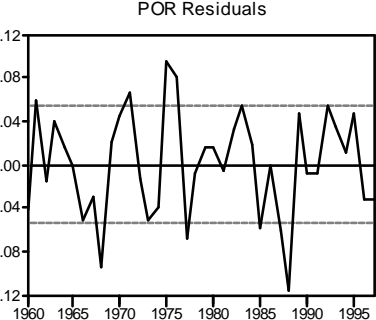

UKD Residuals

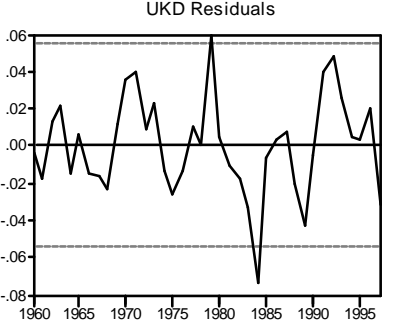

CANResiduals

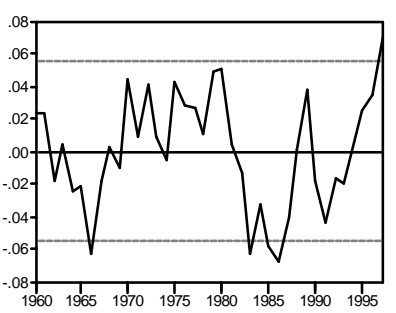

GRE Residuals

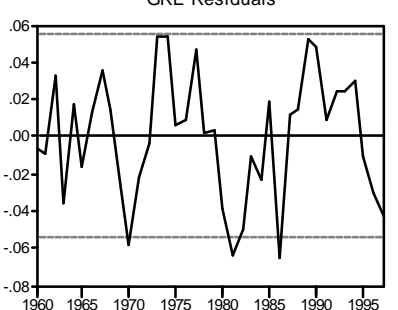

UX Residuals

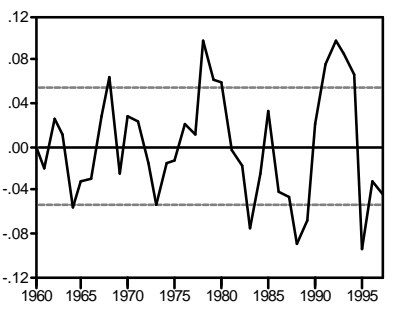

SPA Residuals

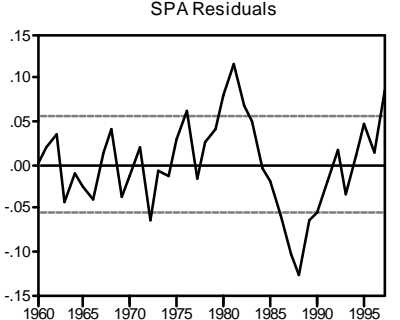

USA Residuals

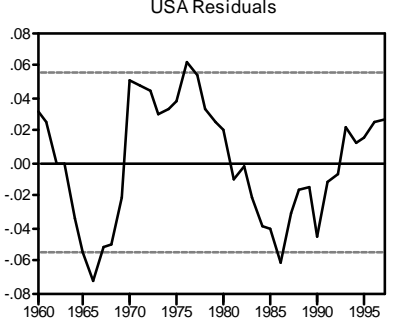

DNK Residuals

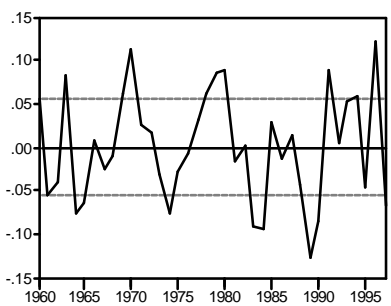

ICE Residuals

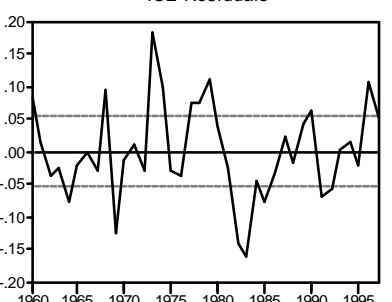

NLD Residuals

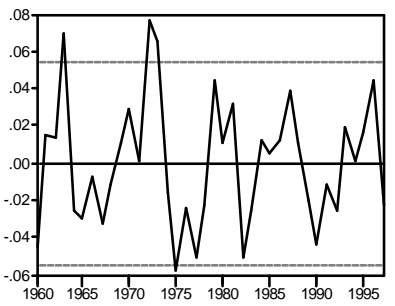

SWE Residuals

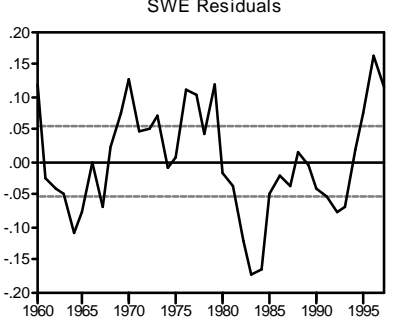

